\title{
44449 - STARCHES USE IN CARDIAC SURGERY: INTER-INSTITUTIONAL VARIABILITY AND TRANSFUSION
}

\section{Keyvan Karkouti, Toronto General Hospital, University Health Network, Toronto, ON, Canada; \\ Stuart McCluskey, Toronto General Hospital, University Health Network;}

BACKGROUND: In cardiac surgery, hydroxyethyl starches (HES) are commonly used to expand plasma volume. There are concerns, however, that HES-related coagulopathy, hemodilution, or both may increase blood transfusion after cardiac surgery. The objective of this multicenter observational study was to survey the current use of HES in cardiac surgery and to analyze its relationship with perioperative blood transfusion.

METHODS: Following REB approval, data were retrospectively collected on 3500 consecutive cardiac surgical patients at seven Canadian hospitals during 2004. Perioperative (day of or day after surgery) HES use was compared among the hospitals using analysis of variance. The relationship between intraoperative (during surgery) HES use and postoperative coagulopathy was assessed using Spearman rank order correlation. The unadjusted and adjusted relationships between intraoperative HES use and perioperative blood transfusion were calculated using logistic regression. Propensity analysis matching was used to verify the logistic regression results.

RESULTS: While 93\% of patients received HES (molar weight $264 \mathrm{kDa}$, molar substitution 0.45 ) intraoperatively, only $43 \%$ received it intraoperatively. For comparison, $11 \%$ of patients received albumin perioperatively. On average, $0.5 \pm 0.6$ units of HES ( 1 unit $=500 \mathrm{~mL})$ were infused intraoperatively and $1.8 \pm 1.1$ units were infused perioperatively. Among the hospitals, intraoperative use ranged from 0.03 to 1.12 units $(\mathrm{P}<0.0001)$, and perioperative use ranged from 1.4 to 2.6 units $(\mathrm{P}<0.0001)$. At admission to ICU, there was a direct relationship between increasing volumes of intraoperative HES infused and elevated INR $(\mathrm{P}=0.03)$, reduced platelet count $(\mathrm{P}<0.0001)$, and reduced hemoglobin $(\mathrm{P}<0.0001)$, but not elevated PTT $(\mathrm{P}=0.1)$. The unadjusted and adjusted (for numerous confounders) odds ratios (ORs) of intraoperative HES used with perioperative blood transfusion are shown in the Table. The findings were consistent among 1700 patients matched based on the propensity of receiving HES intraoperatively (850 per group).

CONCLUSIONS: In these Canadian cardiac surgery centers, HES use is almost universal, but the amount used is highly variable. There is an independent, dose-response relationship between intraoperative HES and blood transfusion. Whether this is a cause-effect relationship or simple association, however, needs to be investigated by adequately powered randomized controlled trials. 


\begin{tabular}{|c|c|c|c|c|}
\hline Blood Product & $\begin{array}{l}\text { Unadjusted } \\
\text { OR* }\end{array}$ & $\begin{array}{l}\text { Unadjusted } 95 \% \\
\text { CI }\end{array}$ & $\begin{array}{l}\text { Adjusted } \\
\text { OR* }\end{array}$ & Adjusted $95 \% \mathrm{CI}$ \\
\hline$\geq 1 \mathrm{U}$ RBC & 2.2 & $1.9-2.5$ & 1.7 & $1.4-2.1$ \\
\hline$\geq 5 \mathrm{U}$ RBC & 1.4 & $1.2-1.6$ & 1.1 & $0.9-1.4^{\dagger}$ \\
\hline $\begin{array}{l}\geq 5 \mathrm{U} \text { RBC or re- } \\
\text { exploration }\end{array}$ & 1.3 & $1.2-1.5$ & 1.2 & $0.98-1.25^{\dagger}$ \\
\hline$\geq 1$ U Platelet & 1.8 & $1.6-2.1$ & 1.3 & $1.1-1.6$ \\
\hline$\geq 1 \mathrm{U} F F P$ & 1.8 & $1.6-2.0$ & 1.5 & $1.2-1.7$ \\
\hline $\begin{array}{l}\geq 1 \text { U Platelet or } \\
\text { FFP }\end{array}$ & 1.9 & $1.7-2.1$ & 1.3 & $1.1-1.6$ \\
\hline
\end{tabular}

* Change in OR per 1 unit of HES transfused $\dagger^{\dagger}$ Not Significant 